\title{
De diarios y redes sociales a literatura de masas: los blogs en manos de los escritores
}

\author{
Begoña Regueiro Salgado \\ Universidad Complutense De Madrid \\ bregueiro@filol.ucm.es
}

\section{Introducción}

\begin{abstract}
Una nueva forma de escritura, fragmentaria e inmediata, pero de aspiraciones literarias, está cobrando auge en Internet a través de los blogs o bitácoras electrónicas que mantienen un batallón de jóvenes escritores mexicanos ${ }^{1}$.
\end{abstract}

Esta frase, escrita en 2006 por un crítico mexicano, en referencia estricta a Mexico, muestra los inicios de una de las revoluciones literarias a las que estamos asistiendo en los últimos tiempos.

Concluida la primera década del siglo XXI, las nuevas formas de literatura que utilizan las herramientas que la informática pone a nuestro alcance, están cobrando auge y piden a gritos un estudio serio y una reflexión teórica que contribuya a su reividicación y mejora.

Una de las variantes más cultivadas de la literatura digital es el blog. Accesible para todo escritor o escribiente y de fácil uso, se ha convertido en uno de los grandes fenómenos del siglo XXI. Ahora

1 Erika P. Buzio, "Hallan en los 'blogs' nueva escritura: Narradores y poetas consideran que se trata de una escritura digital que está cambiando las reglas de sintaxis", Mural (México), 30 de marzo de 2004. Disponible en: http://www.mural.com/cultura/articulo/363762/ [Consulta: 10/10/2009] 
bien, ¿se trata realmente de literatura? ¿qué clase de literatura? ¿literatura popular o de masas?

Los estudios realizados, hasta ahora, se han centrado en otros aspectos o cualidades potenciales de los blogs -blogs como sustitutos de ciertas formas periodísticas, blogs como archivos democráticos de memoria colectiva, blogs como herramientas para la docencia, como redes sociales etc. En este sentido, no será fácil aplicarles el término "literatura". Pero ¿qué ocurre cuando son escritores los que se esconden detrás de la pantalla? Dice María Teresa Vilariño respecto a los creadores de hipertextos: <<El autor (...) es una especie de artesano del que no esperamos grandes trazos de inspiración genial, pero capaz de reunir las habilidades para construir una estructura que comprenda el máximo de bifurcaciones $>>$ (2009:243). ¿Y si ese autor ya ha probado su "inspiración genial" en el formato tradicional del libro? ¿y si las habilidades necesarias para crear bifurcaciones se minimizan?, ¿qué implica la autoría de escritores consagrados en la naturaleza de los blogs? Y, desde el otro lado del espejo, ¿qué busca un escritor cuando decide utilizar este canal?

Esto es lo que abordaremos en este estudio. A partir de una serie de entrevistas a escritores de lengua española que publican en blogs, trataremos de ofrecer el punto de vista de los creadores respecto a un fenómeno que, como señala Santiago Cortés Hernández (2006), ha sido estudiado desde el punto de vista de su potencial comunicativo, el perfil de sus usuarios y sus tendencias temáticas, pero sobre el que se ha reflexionado poco en su faceta de nueva forma de escritura.

\section{Un repaso por la crítica. Características asociadas a los blogs}


En 1994, la apertura pública de la red favorece el desarrollo paralelo de los primeros documentos electrónicos que darán origen a los blogs, entendidos como diarios en línea. La gran explosión se produce entre 1996 y 1997, cuando aparecen los primeros servidores dedicados, exclusivamente, a alojar estos escritos personales. Gracias a ellos, se ponen a disposición del usuario una serie de recursos que permiten combinar texto, añadir imágenes, audio o video y crear hipervínculos, lo que convierte los blogs en espacios propicios para varios tipos de escritura. A partir de aquí, su desarrollo hace que, a principios del siglo XXI, los blogs se hayan consolidado como una nueva forma de escritura personal, que empieza a atraer la atención de estudiosos como Phillipe Lejeune.

Tras el pistoletazo de salida, el estudio de los blogs ha ido en aumento. De este modo, aunque ha sido un enfoque minoritario, podemos encontrar una serie de características que les han sido asignadas en relación a su posible carácter literario.

Si empezamos con Cortés Hernández, las características atribuidas al blog son:

1. Es una escritura de tipo personal.

2. Contiene elementos de distinta naturaleza.

3. Requiere un estudio que va más allá de lo textual, pues:

El discurso no sólo es un acto de comunicación verbal, sino también un proceso de expresión e invención fuertemente basado en elementos figurativos que van desde la elección de un tipo de letra hasta su combinación con imágenes o videos o, incluso, la creación de un hipertexto (Cortés Hernández: 2006: 7). 
Aunque esta afirmación se hace desde el punto de vista del crítico o estudioso y no desde el del objeto de estudio o desde el del creador, nos parece interesante señalar la riqueza de posibilidades semióticas que ofrecen los blogs. Desde los albores de la literatura, los creadores se ha valido de otras artes, como la pintura o la música, para, por medio de las referencias a ellas o de su utilización en forma de ilustraciones o acompañamientos, aportar al lenguaje los valores estéticos y emocionales que pierde con el uso y que hacen de la lengua común una herramienta inútil que el poeta tiene que modificar para llegar a la poesía (Bousoño: 1952). Lo que hasta ahora se ha hecho por medio de alusiones verbales o la utilización de los valores rítmicos o visuales del lenguaje, hoy puede hacerse con la creación de una obra en la que música, imagen y palabra aparecen unidas en un todo en el que cada una de las artes aporta el valor emocional o estético necesario para dar forma a una obra total. Óscar Martín Centeno habla de los "nuevos trovadores" y, en este nuevo trovar, la música o la imagen no "acompañan" al texto, con el riesgo de crear estímulos que distraigan la atención de los lectores; en el siglo XXI, los trovadores pueden conseguir la integración de todos los lenguajes, de manera que, tal como señala Teresa Vilariño (2009):

...la teoría de los tres estadios, ya estipulada por Pierre Lévy, se reafirma en el desarrollo de las nuevas tecnologías, al entrar en funcionamiento de manera simultánea la imagen visual, el texto escrito, el componente oral y el auditivo (Vilariño, 2009: 237).

4.Se trata de un nuevo tipo de literatura popular.

Para apoyar esta afirmación, Cortés aduce una serie de características de esta clase de literatura que considera afines al blog. Se trata de los rasgos relacionados con las prácticas de escritura y el 
perfil de sus autores. De acuerdo con el crítico, que toma como base el estudio de Amanda Lenhardt y Susannah Fox (2006), el $84 \%$ de los autores de blogs los escriben como pasatiempo y sin una razón o finalidad concreta; es decir, lo que Antonio Castillo afirma sobre los escritores de literatura popular, cuando los define como $<<$ escribientes antes que escritores (...) personas para las que la comunicación escrita representa una actividad y no una función>> (Castillo, 2002:25). Por otra parte, el mismo Cortés duda de la calificación de literatura popular al mecionar la discordancia entre los autores populares, de una supuesta extracción social baja, y los autores de blogs, cuya condición socioeconómica les permite, al menos, tener un ordenador y acceso a la red.

$\mathrm{Si}$, como es nuestro caso, nos centramos en los blogs literarios, elaborados por escritores que consideran la comunicación escrita no sólo como una función, sino como un arte al que dedican tiempo y cuidado, parece que la adscripción al género de literatura popular cae por su propio peso.

5. Se trata del primer género electrónico de literatura popular, entendiendo como género una acción retórica que se consolida por la recurrencia de ciertas situaciones comunicativas.

Como tal, cumpliría las características básicas de los géneros electrónicos: no atadura al papel, inclusión de elementos multimedia y etiquetado por ciertos elementos temáticos - permalinks- que lo vuelven buscable y recuperable.

Una primera discrepancia respecto a esta característica la encontramos en José Manuel Martínez Sánchez (2007) que, rotundamente, afirma que, de ningún modo, el blog podría considerarse género literario: <<el blog es una suplantación del libro, es un soporte, y a su vez, es una banalización del mismo>> (4). 
En efecto, parece que el blog es más bien un soporte que un género en sí mismo. Como señala Martínez Sánchez, el soporte digital es una alternativa al soporte libro, y como tal, puede presentar diversas tipologías textuales. Así, un blog puede contener una novela, un relato, un artículo, un ensayo, un poema etc. No se trata de un género literario, tal como los entendemos y los analizamos desde la crítica literaria tradicional. Sí constituye, no obstante, una de las tipologías de la literatura digital y, quizá, sólo desde esa perspectiva, podríamos hablar de género, nunca literario, en el que aparecen algunas de las características de las que habla Stephanie Strickland al definir la poiesis -poesía que, en el contexto digital, se entiende como una mezcla de palabra y código-. Entre estas características se encuentran el intercambio comunicativo simultáneo sobre el que se sustentan las funciones de lectura y escritura, la conexión intensa entre ambas y sus procesos establecidos en tiempo real como ocurre en la oralidad.

6. Tendencia a un contenido personal y autobiográfico.

Esta última característica señalada por Cortés Hernández es discutible desde el momento en que empezamos a contemplar los blogs literarios en la muestra objeto de estudio. Aunque esta afirmación es aplicable a los blogs- diario, el contenido de los blogs literarios se amplía y, si bien pueden contener elementos biográficos reales o ficcionales, no se trata de un contenido exclusivo ni, tan siquiera, predominante.

José Manuel Martínez Sánchez, en su estudio "El blog como fenómeno semiótico" (2007), añade una serie de características que se ciñen al carácter literario de los blogs. 
Ya hemos hablado de su reticencia a considerar los blogs un género, pero, además de esta afirmación, encontramos alusiones a las siguientes características:

1. Ausencia de temporalidad cerrada.

2. Carácter lúdico. Los blogs pueden considerarse juegos interactivos. (Para ver la literariedad de esta característica basta con pensar en las Vanguardias).

3. Pérdida del alma del escritor, dado que todo el mundo puede ser escritor.

Y aquí, de nuevo, surge la pregunta, ¿es que no puede cualquiera ser escritor en cualquier circunstancia? La diferencia no estriba en la capacidad de ser escritor, sino en la de tener acceso al público. Se trata más de una cuestión de filtros que de número de escritores potenciales.

Las dos últimas características que se deducen del artículo son, quizá, las que más nos interesan en relación con lo que intentamos estudiar: ¿en qué momento un blog puede considerarse literario? y ¿cuáles son sus aportaciones?.

La respuesta a la primera de las preguntas se establece, del mismo modo que con los libros, en torno a la función estética. Igual que un texto sólo puede considerarse literatura de acuerdo con unos parámetros estéticos y de voluntad artística, los blogs entrarían en lo literario por medio de la función estética:

En segundo lugar, hay, evidentemente una función estética. Esta enmarca directamente con el carácter literario del blog ya que presume unas motivaciones artísticas por parte de su autor. Desde este lugar podemos entender el blog como algo más que un diario personal o de impresiones de la realidad circundante. Es también un rincón creativo, que, a diferencia 
de las obras literarias, el blog está materialmente vivo, actualizándose (Martínez Sánchez: 2007: 7).

$\mathrm{Si}$, además, tenemos en cuenta lo que Bousoño (1952) considera poesía, veremos que lo que la define son características ajenas al soporte en el que se transmita el texto, por lo que se pueden aplicar de igual modo a un libro o a un blog:

\begin{abstract}
Poesía es, ante todo, comunicación, establecida con meras palabras $^{2}$, de un contenido psíquico sensóreo-afectivoconceptual, conocido por el espíritu como formando un todo, una síntesis. Ahora bien, la expresión idónea que para esa comunicación se requiere, se acompaña secundariamente, de un desprendimiento de placer que se produce en el alma del poeta durante la creación y se mezcla, de inmediato, al fluído anímico que va a emigrar hacia otros seres, hacia los lectores del poema ${ }^{3}$ (Bousoño,1952:18).
\end{abstract}

Por otro lado, el blog entra dentro de la cibernáutica tal como la entiende Couffignal, que, en 1996, afirma: <<Cibernáutica es el arte de la eficacia de la acción>>. Martínez Sánchez señala que estas tres condiciones se cumplen en el blog o, al menos, son el ideal al que se aspira, pues puede hablarse de <<arte en el mensaje, eficacia en el tiempo, actualidad y acción en su retroalimentación: el cumplimieto de la comunicación. La transmisión de la información artística es retroalimentada desde su naturaleza semiológica a través de un soporte informático >> (10). Y aquí entraría una de las aportaciones, o recuperaciones, que proporcionan los blogs: el carácter social de la literatura. Gracias a los blogs podemos resucitar las antiguas tertulias

\footnotetext{
${ }^{2}$ Veremos cómo las nuevas tecnologías permiten utilizar algo más que palabras en esta comunicación.

${ }^{3}$ Las cursivas son del autor.
} 
literarias a través de los comentarios y las simpatías personales que hacen que unos blogs recomienden otros o, directamente, enlacen con ellos ${ }^{4}$. Es cierto que se puede oponer a esta idea el hecho de que, en principio, el primer contacto con un blog suele realizarse por algún tipo de relación personal con su autor, pero lo mismo ocurre en las tertulias literarias convencionales. La diferencia estriba, entonces, en la posibilidad de una expansión "viral"-término utilizado por Óscar Martín Centeno- más efectiva en el mundo de la red. Gracias a ella, la calidad o innovación de un blog podrían captar la atención de "amigos de amigos de amigos" que ya no tienen ningún tipo de relación con el creador, pero que pueden llegar a establecer contacto con él y favorecer un enriquecimiento mutuo. Castelló describe el proceso con las siguientes palabras:

\begin{abstract}
El blog [...] se ha incorporado a mi día a día como un salón virtual o un estudio, uno de esos que siempre he tenido, por el que de cuando en cuando pasa gente: alguien te visita, te comenta algo de lo último que andas haciendo, se produce un intercambio, en mayor o menor grado pero siempre interesante... Y a mi vez, me acerco a su taller, echo un vistazo, comento, disfruto, disfruto mucho: hay creadores, de muy distintas disciplinas, superinteresantes; mucha gente joven que de otro modo no sé si conocería; algunos veteranos con los que he tenido un contacto más personal gracias a esa red que llamamos 'blogosfera' y que, de algún modo nos aproxima, rompe algunas barreras (si se quieren romper), nos hace un poco 'frikis' de una misma hermandad internáutica...(Castelló: 2010).
\end{abstract}

\title{
Los blogs en manos de los escritores
}

Una vez analizado lo que la crítica considera relevante o novedoso en relación a los blogs, llega el momento de estudiar lo que los escritores piensan de ellos. No nos referimos a escribientes, como

\footnotetext{
${ }^{4}$ Idea tomada de Luis Mora: "Blogs: las nuevas tertulias literarias" en Revista Mercurio (Panorama de libros), no87.
} 
han sido caracterizados los autores de blogs, ni a esa masa en la que todos caben a la que se refería Martínez Sánchez, sino a escritores reconocidos y con obra publicada, también en versión impresa, que han decidido hacer de los blogs uno de sus soportes de publicación por las ventajas que estos les aportan.

Antes de sumergirnos en sus testimonios, conviene señalar que el número de blogs literarios crece cada día. Sólo a modo de muestra, podemos afirmar que el número de entradas bajo la búsqueda "blogs de literatura" aumentó del trece de noviembre de 2009 al 22 de febrero de 2010 de, aproximadamente, 4.706.491 a, aproximadamente, 5.530.069. Al centrar la búsqueda en "blogs de literatura en español", el crecimiento sigue siendo significativo -de, aproximadamente, 3.681.191 a, aproximadamente, 4.488.925. Si limitamos el rastreo todavía más a "blogs de creación literaria en español", el crecimiento es algo menor, pero, en cualquier caso, incesante -de, aproximadamente, 485.433 a 488.821.

Entre estos blogs no sólo encontramos páginas personales de autores, sino que abundan las páginas de crítica literaria, las antologías personales de textos o las plataformas interactivas de revistas literarias o grupos literarios que hallan en el blog una manera de hacerse visibles en la red.

Si pasamos al análisis de lo que los escritores -ya hemos dicho a quiénes nos referimos- esperan y buscan en los blogs, llama la atención descubrir que, en múltiples ocasiones, sus preferencias se decantan por aspectos que la crítica apenas ha anotado.

En primer lugar, hemos de señalar la importancia otorgada al hecho de que los blogs impliquen un contacto directo con el público y una ausencia de filtros editoriales a la hora de llegar al lector. 
Es cierto que autores como Celestino Miguel de Corral consideran que la proliferación de poesía en la red que implica la falta de filtros, trae consigo una devaluación de la calidad, pues $<<$ los blogs son de esta forma una especie de almacén y amontonamiento de poesía que lo que hace es devaluarla por el exceso que representa >> (Miguel del Corral: 2009:11); pero ¿no es cierto que el filtro final to impone el lector? No olvidemos que la multiplicación de los blogs que pueden ser consultados también significa que el lector tiene infinitas posibilidades de consulta, por lo que aquellos blogs que no alcancen un mínimo de calidad y de innovación y que no sean actualizados de forma regular dejarán de ser visitados rápidamente.

En cualquier caso, la opinión mayoritaria de los escritores es que esta falta de filtros editoriales supone una enorme ventaja. Álvaro Muñoz Robledano habla de: <<Autores expuestos a los lectores sin intermediarios oscuros, al margen del compadreo y las técnicas mafiosas que dominan la edición >> (Entrevista personal al autor, 2010), y añade: <<pienso que en los blogs, en todo lo digital, está el futuro de la poesía. Pues el presente se ha construído con dinero, y se supone que este negocio no iba de eso>> (ibídem).

En la misma línea, Cristina Rivera Garza, afirma:

Me intrigaba en ese momento, así lo quiero creer, la democracia irreverente de la blogósfera -el hecho de escribir a la par y junto con hombres y mujeres para quienes la escritura no era una profesión ni un oficio sino un gusto, un ejercicio, acaso un reto, algo encontrado al azar en el ciberespacio. Me tentaba el anticapitalismo mordaz de la blogescritura- [...] Me subyugaba completamente la inmediatez y la antijerarquía de la publicación y la posible, y a fin de cuentas real inmediatez de la lectura y la respuesta (en You-Jeong Choi: 2006, a partir de Cristina Rivera Garza, "Blogsívela. Escribir a inicios del siglo XXI desde la blogósfera" Palabra de América. Seix Barral, Barcelona, 2004, p. 169). 
La autora habla, además, de inmediatez de la publicación. Es interesante subrayar este dato, porque nos lleva a la valoración de otras ventajas 0 , al menos, diferencias existentes entre la publicación en papel y la creación de un blog. La no existencia de filtros editoriales no sólo evita el posible amiguismo de las editoriales sino que influye en otros factores. En primer lugar, el carácter internacional y supranacional de la red favorece un aumento importante de los lectores potenciales y limita el tiempo que separa al autor del lector, por no insistir en el hecho de que comparten un mismo espacio. La red no es un constructo nacional, no es un espacio nacional; sea cual sea nuestra nacionalidad, cuando navegamos por la red, pertenecemos a ese espacio, al que también pertenecen los demás lectores o navegadores, sean cuales sean sus procedencias. De hecho, en la red nadie está ligado a ninguna nación si no es su deseo expreso, como prueba el que en los perfiles de muchos blogeros no aparezca la "ubicación". La vocación de los blogs es hispánica o, incluso, internacional. No siempre resulta fácil verificar si esta vocación se cumple o no, ya que la única forma de rastrear la procedencia de los lectores de un blog es que ellos mismos decidan darse a conocer como seguidores y que, a su vez, decidan definirse en relación a una nación ${ }^{5}$. Sin embargo, incluso en esta limitada muestra de lectores con nombres y apellidos encontramos algunos como Giovanni Colazos (seguidor del blog "El hombre azul", de Óscar Rozalén) que se sitúa entre Madrid y Lima. Del mismo modo, en un mundo donde lo "trans-" está cobrando fuerza y donde las fronteras se van diluyendo, no es extraño encontrar blogeros españoles que están ubicados en Bélgica (Lydia Fernández, por ejemplo, autora del

\footnotetext{
${ }^{5}$ En cualquier caso, la limitada representatividad de estos se ve en blogs con contadores de visitas que marcan más de mil, mientras que cuentan con menos de un centenar de seguidores. Así, por ejemplo, el blog "Alzando el vuelo" de Petit Suise, marca 12663 entradas y sólo tres seguidores y el blog del artista Pablo Gallo señala 30693 visitas y tan sólo ochenta seguidores.
} 
blog "A new room of one's own") $O$ en Inglaterra (como Borja Menéndez, autor de "El almagesto"), que introducen sus entradas en distintas lenguas y siguen blogs escritos en España.

Por otro lado, la falta de trasductores e intermediarios hace al autor dueño completo de su obra, y su accesibilidad para los comentarios, sugerencias o preguntas de los lectores lo desacraliza y acerca, lo que contribuye a un diálogo literario más fructífero. $<<$ Los comentarios te animan $>>$, dice Julio Castelló (entrevista personal con el autor).

A esto alude, también, Lorenzo Silva que, en el prólogo de La isla del fin de la suerte, explica su "experimento" de autoría "compartida" con las siguientes palabras:

No sólo se enconmendó al lector la toma de decisiones normalmente reservadas al novelista (cómo terminar cada capítulo, cómo terminar la novela); sino que también se le dio la posibilidad de influir en tiempo real en el proceso de creación, que, por lo común, resulta más o menos inmune a su lectura (en tanto que esta se produce a posteriori, cuando la obra está concluida). Y el novelista, por su parte, pudo conocer mientras la historia avanzaba los efectos que iba produciendo en quienes la leían, y ajustar su invención en función de las reacciones que observaba en sus destinatarios.

\section{$(\ldots)$}

...me gusta pensar en esta novela como en una obra compartida, en la que la autoría ve resquebrajado su tradicional carácter individual para abrirse a la multitud. Pero no a una multitud cualquiera, sino a esa multitud de lectores activos y generosos que constituyen, a mi juicio, la única y verdadera república de las letras (por más que algunos pelmazos y no pocos pedantes pretendan apoderarse de la expresión para ponerla al servicio de sus rancios intereses) (Silva: 2008: 9).

La falta de intermediarios supone, pues, un cambio en la situación del autor, pero también en la del lector, al que se reivindica, 
al que se le da protagonismo y al que la obra llega a cambio, sólo, de su interés por ella:

Nadie tuvo que pagar un duro ni acreditar ningún otro requisito que el de saber leer y poder manejar un ordenador para participar en el juego. (...) me pareció una buena manera de dar al lector el protagonismo que a veces se le niega, al relegarlo al papel de consumidor de ejemplares que sostiene, mediante el pago de su precio, las finanzas y el prestigio, o lo que es peor, la vanidad de quienes escriben (Silva: 2008:10).

Si en cualquier manifestación de literatura digital, el concepto de lector evoluciona al de navegante, constructor y prosumidor (utilizando términos de Vilariño, 2009), en muchos de ellos, <<la aparente libertad concedida al lector no hace más que reforzar la posición soberana del autor>> (Vilariño, 2009: 243). Sin embargo, como defiende Landow y como acabamos de ver en palabras de Lorenzo Silva, los blogs constituyen un hipertexto atípico, donde la libertad y el poder del lector son reales, pues se le permite no sólo establecer un orden de lectura/navegación, sino, también, añadir sus propios enlaces y comentarios. Se trata pues, más que en ningún otro caso, de un hipertexto colaborativo en el que $<<$ participan los usuarios incentivados por el propio autor-promotor, creando un resultado de autoría colectiva infinita >> (Vilariño, 2009: 242).

Así, el blog permite un acercamiento real entre escritor y lector, lo que constituye para autores como Silva una de las mayores gratificaciones: <<Sentir al lector, a menudo con nombre y apellidos, sentado a mi lado y animándome a continuar >> (12). Lo mismo pondera Castelló:

mi intención en el blog es sencillamente la de comunicar: mantener un canal abierto para que en cualquier momento alguien pueda conocer las idas y venidas de mis pensamientos, mis emociones, mis vivencias, con ese característico exhibicionismo de los creadores que no lo son de bolsillo o de cajón, puramente onanistas. Entiendo que es un modo fantástico para que la obra o parte de la obra de 
alguien se airee y se convierta en conversación desde un principio y no en, a veces penoso, monólogo (Castelló, entrevista personal con el autor).

Asimismo, esta "creación compartida", esta dinámica de interacción, este diálogo hacen de la literatura un juego y de $<<$ la diversión compartida, su principal objetivo>> (Silva: 2008:14). Es cierto que esta afirmación no es válida para todos los blogs ni es la motivación que mueve a todos los escritores, pero sí que constituye un factor importante y una de las experimentaciones posibles que ofrecen los blogs.

con la interacción directa de los lectores se convierte en una obra en marcha de corte dramático (por el diálogo entre personajes). Al final termina siendo probablemente una forma de autoficción (y heteroficción, por lo que toca a otros) (Silva: 2010: entrevista personal con el autor).

La experimentación se convierte de esta forma en otro de los valores más apreciados de los blogs. Dice Vilariño:

La combinación de Internet y literatura produce una mezcla explosiva, a la que no es ajeno el desarrollo de un trabajo interactivo o la posibilidad de experimentar con nuevos géneros literarios que los sociólogos, pragmáticos, filólogos tenemos la obligación de investigar (Vilariño: 2009:241).

Una forma de innovar es la que acabamos de señalar, realizada por Lorenzo Silva en la novela La isla del fin de la suerte, pero no es la única. John Updike, ganador del Premio Pulitzer y uno de los grandes de la literatura norteamericana, realizó el experimento de escribir el primer párrafo de una novela que fue continuada, a través de Internet, por los lectores-escritores navegantes dispuestos a ensayar en esta forma de escritura colectiva. 
Asimismo, la incorporación del lenguaje ciber y de los blogs como materia literaria va en aumento. Choi habla de la obra de Edmundo Paz Soldán, El delirio de Turing (Alfaguara, 2004) y de En busca de Klingsor (Seix Barral, 1999), de Jorge Volpi, cuyo protagonista se llama Gustavo Links. Del mismo modo, no hemos de olvidar El blog del Inqusidor (Destino, 2008), de Lorenzo Silva; novela en la que no sólo se hace núcleo generador de la historia la relación que se establece entre el escritor de un blog y una de sus lectoras -relación en la que aparece el juego de autoficcionalización que antes comentábamos-, sino que aparecen referencias a cada una de las partes del blog - perfil del autor, entradas, fechas etc.

La experimentación, no obstante, va más allá. La falta de intermediarios permite, a su vez, la propuesta de modelos diferentes y convierte a los blogs en <<cauce para propuestas radicales, ajenas a cualquier tipo de corriente, dominante o dominada>> (Muñoz Robledano: 2010: entrevista personal al autor).

La opción de incluir imágenes, vídeos, música y todo tipo de elementos contribuye, también, a esta oferta de novedad y el enriquecimiento semiótico se ha convertido en una de las posibilidades que brindan los blogs más valorada por los escritores: $<<$ me interesa también como puzzle, como hipertexto que puede acoger prácticamente cualquier cosa, propia o ajena. Como patchwork de historias, voces, textos, referencias, etcétera $>>$, dice Lorenzo Silva (2010). Y, en la misma línea, Julio Castelló afirma:

El blog me ha servido para elaborar y desarrollar un tipo de creación que de otro modo no me habría sido posible llevar adelante (o habría sido terriblemente complicado): la fusión de fotografía y poesía, poesía y fotografía, en perfecta simbiosis (Castelló: 2010, entrevista personal). 
Es cierto que las posibilidades tecnológicas que ofrece un blog son limitadas y que, para los autores que buscan hacer poesía digital, el espacio ideal es la página web, -por eso la web es el destino final de muchos de los autores que empiezan con la publicación de blogs-; sin embargo, el blog, dentro de sus limitaciones, también ofrece ventajas. Así, la simplicidad en su manejo permite a todos los escritores entrar, de algún modo, en el mundo de lo digital y acercarse, tímidamente, a la plenitud de significados y fusión de artes que puede conseguirse en una página web. Uno de los obstáculos principales que existen a la hora de crear o leer en internet, la alfabetización informática, queda resuelto así, pues incluso el autor que no posea suficientes conocimientos informáticos será capaz de estar y "existir" en internet con la independencia que ofrece la no necesidad de buscar un nuevo intermediario entre el lector y el autor -el programador, en este caso. Por eso, Castelló define el blog como:

herramienta, que, frente a la página web, posee una agilidad versátil y multidisciplinar y un manejo sencillo al alcance del simple usuario, y día a día podemos verlos o leerlos, o ambas cosas, haciendo gala de una productividad envidiable.

Asimismo, la interacción es más fluida en los blogs que en las páginas web.

A la vista de todo esto, podemos decir que la libertad creativa y la libertad en las relaciones que se establecen con los lectores son las dos facetas más apreciadas por los escritores, que recurren a los blogs para enriquecer sus textos y enriquecer sus relaciones con el público. < <El blog te da una absoluta libertad; luego tú te tomas la que quieres o la que necesitas, pero nadie le pone condiciones a tu creatividad. Cada cual se autorregula>>, dice Castelló. Son, pues, textos libres, autónomos e independientes del formato libro en los 
que el autor puede investigar y probar nuevos estilos que llegan, incluso, a estar condicionados por el nuevo medio, que determina, así, la evolución posterior del autor.

Lo cierto es que el medio, en cierto modo, a mí me condiciona. Decidí al poco de abrir la bitácora algo tan 'tonto' como no publicar textos largos (me cansa leerlos en general en el ordenador), y eso me empujó a una labor de condensación que ha marcado una parte de mi producción literaria (Castello: 2010).

Asimismo, el blog funciona como una nueva forma de marketing en la que el escritor, por medio de la calidad y el entusiasmo, puede conseguir la expansión viral, que le haga llegar a personas de todo el mundo con sus mismas inquietudes. Así, un movimiento artístico minoritario seguirá teniendo la forma y la fuerza de un grupo en el momento en el que los miembros de cada parte del mundo puedan actuar juntos en la red. Libertad artística sin fronteras, sin restricciones y sin filtros. El sueño de cualquier escritor.

\section{Conclusiones}

Llegados a este punto, es momento de preguntarse de nuevo si los blogs pueden considerarse vehículo de literatura popular o, por el contrario, deberíamos limitarnos a hablar de literatura de masas, en cuanto a su capacidad de difusión, pero de masas selectas, por la especilización que permite la variedad de blogs a los que se puede acceder en la red.

Dice Álvaro Muñoz Robledano: $<<$ Yo no hablaría de literatura popular, sino de literatura a secas $>>$ (2010), y Lorenzo Silva añade: $<<$ Forma de literatura popular... Bueno, creo que es un género neomemorialístico, un dietario híbrido, a veces diarístico, a veces 
ensayístico o aforístico, a veces epistolar, a veces panfletario>> (2010). Es decir, como señalaba José Manuel Martínez Sánchez, un soporte, no un género. $Y$ como soporte, su carácter digital le permite una difusión impensable en cualquier otro medio. Igualmente, como soporte, sus características específicas lo hacen medio perfecto para la experimentación, para la investigación artística...para la vanguardia. ¿Literatura popular? Lo será la de aquellos que limiten sus contenidos al ámbito de la literatura popular. Todos aquellos que quieran ir mucho más allá, encontrarán también en los blogs, como paso previo a las páginas web, las alas que les ayuden a remontar el vuelo.

\section{BIBLIOGRAFÍA}

BOUSOÑO, Carlos: Teoría de la expresión poética (hacia una explicación del fenómeno lírico a través de textos españoles), Madrid, Gredos, 1952.

CASTILLO, Antonio: "De la suscripción a la necesidad de escribir" en La conquista del alfabeto. Escritura y clases populares, Gijón, Trea, 2002, pp. 21-31.

CORTÉS HERNÁNDEZ, Santiago: "El blog como un tipo de literatura popular: problemas y perspectivas para el estudio de un género electrónico" en Culturas populares.Revista electrónica 3, 2006. Disponible en

\section{http://www.culturaspopulares.org/textos3/articulos/cortes.pdf}

[Consulta: 16/10/2009]

CHOI, You-Jeong: "La literatura en el mundo virtual: los escritores y el "blog" en América Latina" en Espéculo. Revista de 
estudios literarios. Universidad Complutense de Madrid, 2006. Disponible

http://www.ucm.es/info/especulo/numero33/blogam.html [Consulta: 16/10/2009]

LANDOW, George: Hypertext: The convergence of Contemporary Critical Theory and Technology, Baltimore, The John Hopkins University Press, 1992.

LENHART, Amanda; FOX, Susannah: "Bloggers. A portrait of the internet's new storytellers", 2006. Disponible en http://www.pewinternet.org/pdfs/PIP\%20Bloggers\%20Report\%20Jul y\%2019\%202006pdf [Consulta 16/10/20010]

MARTÍNEZ SÁNCHEZ, José Manuel: "El blog como fenómeno semiótico", en Tonos. Revista electrónica de estudios filológicos, no13, 2007. Disponible en http://www.tonosdigital.es/ojs/index.php/tonos/article/viewArticle/11 Z [Consulta: 15/19/2009]

MIGUEL DEL CORRAL, Celestino: "Poesía y blogs", en Voces del extremo, Poesía y tecnología, Béjar, Excmo.Ayuntamiento de Béjar, 2009.

VILARIÑO, María Teresa: "La cultura digital en los estudios literarios. CIBER/TEXTUAL/ESPACIALIDADES poéticas" en Teoría literaria con voz propia, ed. SANZ Amelia, Madrid, Arco Libros, Colección Lecturas, 2009.

Entrevista personal con LORENZO SILVA, http://lorenzosilva.blogspot.com/, "Los trabajos y los días", [Enero 2010], JULIO CASTELLÓ, http://juliocastello.blogspot.com/, [Enero 2010], ÁLVARO MUÑOZ ROBLEDANO, http://amrclus.blogspot.com/ "Clus", [Enero 2010] $y$ ÓSCAR MARTÍN CENTENO, http://web.mac.com/grupoartistico8/CENTENO/Blog/Blog.html, [Enero 2010] 